\title{
EL SILENCIO DE LA SIRENA: Lo Sublime en Alejandra Pizarnik
}

\author{
Julieta Lerman \\ Doctoranda en la Universidad de Buenos Aires - UBA
}

\begin{abstract}
Resumen: Algunas poéticas de las décadas del cincuenta y del sesenta parecerían constituirse en torno a un vacío, un silencio que a veces inspira la palabra poética y otras veces la aborta. Esa ambigüedad, característica de la poética de Alejandra Pizarnik, podemos entenderla como una "reedición" de la estética de lo sublime. Lo sublime es un concepto estético-filosófico que plantearon filósofos como Inmanuel Kant y Edmund Burke para pensar el arte romántico y, en el siglo XX, otros autores como Jean-François Lyotard, lo retomaron para analizar el arte de vanguardia. Así, lo sublime nos permite repensar la poética de Pizarnik en sus coincidencias y oposiciones a otras de la tradición moderna (como la de Charles Baudelaire) o de las vanguardias latinoamericanas (como Oliverio Girondo y Vicente Huidobro).
\end{abstract}

Palabras-llave: poesía; Pizarnik; silencio; estética de lo sublime

Abstract: Some poetics of the fifties and sixties seem to be built around an emptiness, a silence that at times inspires the poetic word and at other times aborts it. We can understand this ambiguity, characteristic of Pizarnik's poetics, as a return on the aesthetic of the sublime.

The sublime is an aesthetic-philosophical concept raised by Immanuel Kant and Edmund Burke among other philosophers to approach the romantic art, and, in the twentieth century, other authors such as Jean-François Lyotard, returned to it to analyze the avantgarde art. Thus, the sublime allows us to rethink Pizarnik's poetics in its oppositions and affinities with other poetics of the modern tradition (such as Charles Baudelaire) or the avant-garde poets of Latin America (such as Oliverio Girondo and Vicente Huidobro).

Key words: poetry; Pizarnik; silence; sublime aesthetic

Las sirenas tienen un arma más terrible aún que el canto: su silencio. Aunque no ha sucedido, es quizá imaginable la posibilidad de que alguien se baya salvado de su canto, pero no ciertamente de su silencio.

Franz Kafka

En su artículo "Hölderlin y la esencia de la poesía", Martin Heidegger lee en la poesía de Friedrich Hölderlin un origen puesto que ésta, según el filósofo, volviéndose sobre sí misma, instaura de nuevo su esencia. Heidegger entiende esa instauración como una fundación histórica: instaurar de nuevo la esencia de la poesía -que había sido desplazada de la polis de Platón-, es instaurar un nuevo tiempo histórico que es "el tiempo de los dioses que han huido y del dios que vendrá" (p.147). Se trata de un entre-tiempo en el que la función del poeta queda de algún modo suspendida, ya que según la concepción romántica éste constituye una suerte de mediador entre los Dioses, que dan el habla, y el pueblo, para quien el poeta "traduce" y hace llegar los nombres de los dioses. Esa lectura, realizada desde el siglo XX, acaso pueda entenderse en los términos de Jean Paul Sartre 
(1947), según quien la intención sacralizadora que hasta comienzos de siglo era exclusiva de la fe religiosa, en muchos casos, se trasladó al arte. De alguna manera, Heidegger sitúa a la poesía en el lugar donde antes estaba Dios y se interesa especialmente en la obra de Hölderlin porque según él, en esa época ausente de divinidades, el poeta alemán persigue el rastro sagrado que han dejado los dioses en su huida.

En ese contexto, en algunos poetas que publican sus obras en las décadas del cincuenta y del sesenta, podríamos leer la instauración de un nuevo origen donde ya no habría ni dioses ni rastros de su huida sino un vacío puro, una nada, un silencio ${ }^{1}$ que a veces inspira la palabra poética (e incluso puede coincidir con lo que se concibe como “poético"), y otras veces la aborta ${ }^{2}$. Esa ambigüedad, característica de la poética de Alejandra Pizarnik, podemos entenderla como una "vuelta" o "reedición" de la estética de lo sublime.

Según la definición de Immanuel Kant, el sentimiento de lo sublime es una mezcla de placer y de pena que proviene de la evocación de algo muy poderoso, un absoluto del cual la imaginación no logra suministrar una representación. Pero este fracaso y pesar de la expresión provoca a su vez el placer de atestiguar incluso lo que no puede ser visto, por eso Kant propone el concepto de "presentación negativa" para pensar la obra de arte sublime, característica del romanticismo. Pero si en el arte y en la sensibilidad romántica predominaba la concepción de un sujeto trascendental que remitía a Dios, y lo inexpresable e indeterminado encontraba allí también de algún modo su fundamento, en el siglo XX se produce un giro. En el texto "Lo sublime y la vanguardia" Jean-François Lyotard se pregunta cómo es que a mediados del siglo XX, el término de lo sublime vuelve en palabras de un pintor neoyorkino judío, Barnett Newman, que, entre otras alusiones, en 1948 escribe un ensayo titulado The sublime is now. La respuesta que aventura es que la obra de Newman, a pesar de haber roto con la elocuencia del romanticismo, mantiene la misión central de que la obra sea testigo de lo inexpresable. Retomando la definición de Edmund Burke, que plantea que lo sublime es un sentimiento suscitado por la amenaza (el terror) de que no suceda nada más, Lyotard propone que en la obra de Newman, lo sublime tiene que

\footnotetext{
${ }^{1}$ Una figura emblemática en ese sentido es la de Paul Celan, por su trabajo con la lengua alemana en la posguerra. En el poema "Salmo" del libro La rosa de nadie de 1963, leemos: "Nadie nos plasma de nuevo de tierra y arcilla,/ nadie encanta nuestro polvo./ Nadie.// Alabado seas tú, Nadie." Según Alain Badiou (1990), Celan concluye a Hölderlin y cierra una edad del pensamiento (la "edad de los poetas") en la que la filosofía y la poesía estaban de algún modo fusionadas.

2 Distintos estudios analizaron esa relación entre la escritura, o el arte en general, y el silencio, y la creciente tendencia en esos años a concebir que, en medio de la "inflación verbal", como la llamó George Steiner (1967), "hablar es decir menos", y viceversa. En ese sentido, Susan Sontag (1967) denominó "estética del silencio" a las propuestas que utilizaban estrategias de reducción y empobrecimiento para potenciar la intensidad de la expresión.
} 
ver con la presencia misma del cuadro, con el "acontecimiento visual" que constituye: lo define como "instante plástico". Lo inexpresable, dice Lyotard, no es aquí algo de otro mundo y de otro tiempo sino que reside en que suceda algo, ahora, en que haya cuadro: eso es sublime. Para Lyotard, la vanguardia pertenece a la estética de lo sublime porque se aferra a la pregunta “¿sucede?”, es decir, ¿hay cuadro? ¿Hay arte? Más que afirmarse en un tema, dice Lyotard, la vanguardia interroga o desafía mediante la obra como "acontecimiento".

Por su parte, en "Goces del moribundo (De lo sublime en Espantapájaros de Oliverio Girondo", Gonzalo Aguilar matiza la hipótesis de Lyotard y aventura que resulta improbable que todas las vanguardias hayan estado comprometidas con el concepto de lo sublime, como postula el filósofo francés, pero que en algunos movimientos sí puede reconocerse un intento programático de incorporar lo sublime (en el uso del feísmo y de materiales tradicionalmente no artísticos por ejemplo) como forma de discutir la noción de lo bello que estructuraba el arte modernista. En las vanguardias literarias latinoamericanas, dice Aguilar, lo sublime irrumpe con Trilce, de César Vallejo, y aparece como uno de los postulados creacionistas de Vicente Huidobro, que habla de un "sublime de bolsillo". En el caso de Girondo, Aguilar analiza el recorrido que va desde el epígrafe de Veinte poemas para ser leídos en el tranvía, de 1922 ("Ningún prejuicio más ridículo que el prejuicio de lo SUBLIME" -con mayúsculas en el original-) a la resignificación que aparece en Espantapájaros, su tercer poemario, de 1932, donde vuelve a aparecer este concepto de otra manera (por ejemplo, en el poema 10 se lee "¡En la vida hay que sublimarlo todo!" "Yo he optado, definitivamente, por lo sublime”). Tanto Vallejo como Huidobro y Girondo, "miniaturizan" lo sublime hasta convertirlo en un "amuleto", dice Aguilar5.

En el caso de Alejandra Pizarnik, como fue señalado en múltiples ocasiones, se conjuga, ante todo, una fuerte impronta surrealista con una fuerte impronta romántica, pasando por los poetas malditos (en especial Arthur Rimbaud) y la poesía pura de Stéphane

\footnotetext{
${ }^{3}$ Otros autores, como Fredreic Jameson (1990) en Ensayos sobre el posmodernismo, retoman también el concepto kantiano para pensar el arte. Jameson habla de un "sublime posmoderno" que atestiguaría lo irrepresentable del sistema capitalista.

4 "Nada se le parece en el mundo externo [al poema]; hace real lo que no existe, es decir, se hace realidad a sí mismo. (...) Los poemas creados adquieren proporciones cosmogónicas; os dan a cada instante el verdadero sublime, este sublime del que los textos nos presentan ejemplos tan poco convincentes. Y no se trata del sublime excitante y grandioso, sino de un sublime sin pretensión, sin terror, que no desea agobiar ni aplastar al lector: un sublime de bolsillo." Huidobro en Aguilar. Episodios cosmopolitas en la cultura argentina, p.238.

5 "El hecho de que sea "de bolsillo" abre una serie de connotaciones (mercantiles, utilitarias, en fin, civilizadas) que miniaturizan lo sublime hasta convertirlo en algo así como un amuleto. ¿Qué queda de la definición de Burke, para quien lo sublime no podía existir "sin terror"? En el caso de Huidobro, la relación de discordancia entre el poema y el absoluto (el cosmos) se resuelve en la pura inmanencia del poema y en su potencia para crear, podríamos decir usando términos de Burke, un "infinito artificial"." Aguilar. Ob. Cit, p. 238.
} 
Mallarmé. Aunque hasta donde sabemos no aparecen en sus textos referencias directas al concepto de lo sublime, podemos vincularlo a su poética porque una de las guías principales de la exploración de su escritura parece ser la intención de decir lo indecible, de dar testimonio de lo irrepresentable ("hablo de lo que no es" dice un verso de Los trabajos y las noches, de 1965). En ese sentido podemos leer la evocación de absolutos como la muerte o el nombre de Dios, como propone Tamara Kamenszain (2010, 2000), pero también la violencia social, política, humana y los monstruos que pueden engendrar y de los que Pizarnik también fue testigo. La frase final de La condesa sangrienta puede leerse como una reflexión acerca del delicado límite entre la libertad y la monstruosidad humana: "Ella [la condesa] es una prueba más de que la libertad absoluta de la criatura humana es horrible."

De esta manera, uno de los núcleos centrales que atraviesa toda la escritura de Pizarnik, es el problema de la representación que, retomando el concepto de Kant, en Pizarnik parece ser siempre negativa. Como postula María Negroni (2003), el poema escrito en 1956 "alejandra alejandra/ debajo estoy yo/ alejandra", convertido en emblema de la poética pizarnikiana ("aleph vertical" o "mantra visual" lo llama Negroni), señala la idea de descenso asociada al acto creador y exhibe el divorcio entre las palabras y las cosas, que constituye uno de los nudos principales de su obra.

También, podemos leer lo sublime en Pizarnik en las dos direcciones correspondientes a las dos partes de su obra que ha señalado la crítica. Por un lado, en la pena-placer del fracaso-logro de la expresión (sería la parte "lírica" de su obra, sus poemas) y, por otro lado, en el trabajo con lo monstruoso, lo feo, y los materiales no "poéticos" en sentido tradicional (que correspondería a lo que Pizarnik llama sus "prosas corrosivas"). Es decir, lo sublime parecería configurarse a partir de cierta concepción de belleza que aparece indisociable de la pena, la melancolía, la muerte, el mal, lo monstruoso. Como hemos mencionado, esa concepción la encontramos tanto en los poetas malditos como en los románticos y en los surrealistas. En ese sentido, dos conceptos vinculados a lo sublime resultan emblemáticos para pensar la poética de Pizarnik. Por un lado, el de "belleza convulsiva" de André Breton, uno de los autores favoritos de la poeta, que aparece en la frase final de L'amour fou: "LA BEAUTÉ SERA CONVULSIVE OU NE SERA PAS" (en mayúsculas en el original). Y, por otro lado, lo que podría denominarse la "belleza de la desdicha" ("beauté du Malheure") propuesta por Charles Baudelaire y que incluye siempre la melancolía. Dice en sus diarios el poeta francés: "La mélancolie en est pour ainsi dire 
l'illustre compagne [de la Beauté], à ce point que je ne conçois guère un type de beauté où il n'y ait du Malheure."

Jean Starobinski (1989) propone que no sólo el concepto de belleza en Baudelaire es indisociable de la melancolía sino que ésta constituye su condición sine qua non y que para Baudelaire algo resulta más atractivo cuanto más melancólico es. Es así, por ejemplo, que Satán aparece como el tipo más emblemático de belleza masculina. Lo mismo podríamos decir a propósito de Pizarnik, y hacerla decir a ella, parafraseando a Baudelaire, "no concibo un tipo de belleza en la que no haya Muerte". Porque en Pizarnik lo sublime no tiene que ver con el amor, como en Breton, ni con las irrupciones de lo efímero, como en Baudelaire (que, en todo caso, estaría más cerca del sublime de Girondo). La muerte parece ser la principal fuente de lo sublime en la estética de Pizarnik, el absoluto que la escritura quiere testimoniar. "Muerte, entonces, parece ser el nombre que Pizarnik le da a lo que no tiene nombre", señala Tamara Kamenszain (2010). "Poner las cosas en sublime", como llama Gonzalo Aguilar a dicho procedimiento en la poética de Girondo, es, en Pizarnik, adoptar o más bien, "encarnar" el punto de vista de la muerte. Muerte del sujeto, muerte del sentido, muerte de Dios, del lenguaje, del poema. El punto de vista de la muerte que configura lo sublime es lo que Pizarnik llama en una entrada de su diario el punto de vista del "reverso del mundo", que busca ver lo que otros no ven, escribir lo que no se puede escribir, decir lo que no se puede decir. En sus Diarios leemos:

\footnotetext{
Esta manera de ser me hace perder y ganar. Perder en cuanto a que me encadena, me impide enfrentar el mundo, y más aún, me deja a merced del mundo. Pero, por otra parte, en el reverso del mundo, donde yo estoy, se ven muchas cosas vedadas para los otros. (p.103)

Yo sufro mucho cuando escribo y mi desdicha se incrementa. Pero B[orges] eligió la literatura posible -o la clásica- en tanto yo escribo lo que no se puede y por eso engendro monstruos disonantes. (p.461)
}

En Pizarnik, lo sublime, que había sido "miniaturizado" por sus antecesores, vuelve a agrandarse, sale del "bolsillo" de Huidobro y busca de alguna manera "aplastar al lector", como decía el poeta chileno, con la menor cantidad de palabras posible. Lo sublime así agigantado, convierte a la poesía en un mundo autónomo pero ambiguo, tensado entre la dicha y la pena del decir. "La poesía, no como substitución, sino como creación de una realidad independiente - dentro de lo posible- de la realidad a que estoy acostumbrada."7

\footnotetext{
6 "La melancolía es, por así decir, la ilustre compañera [de la Belleza], a tal punto que no concibo un tipo de belleza donde no haya Desdicha." Baudelaire en Starobinski, La mélancolie au miroir. Conférences, essais et leçons du Collège de France, p. 23.

${ }^{7}$ Pizarnik. Diarios, p.79.
} 
Por un lado, la poesía es un lugar "donde todo es posible"8 (y aquí coincide en cierto punto con el postulado creacionista: el poema como "hecho nuevo" al que "nada se le parece en el mundo externo; hace real lo que no existe, es decir, se hace realidad a sí mismo", dice Huidobro). Pero, por otro lado, el poema no logra "hacerse realidad": siempre queda lejos de lo que quiere decir, envejece demasiado rápido. "He querido decir la violencia y sólo atiné a recordar el lenguaje de la sumisión" leemos en otra entrada de su diario de 1968 (p.457). La palabra siempre termina fallando, el poema no dura, fracasa al quedar congelado en su retórica, desgajado del aquí y ahora del mundo real donde "todo es posible/ salvo/ el poema".

De esta manera, podemos pensar que al agrandarse lo sublime, lo que se miniaturiza y se convierte en amuleto es el poema ${ }^{10}$. Escrito generalmente todo en minúscula y casi sin signos de puntuación, el poema-amuleto extrae su narración de lo inenarrable. Se trata de una "narrativa minimalista", dice Kamenszain en La boca del testimonio, "ese cuento que cada palabra sola narra." "11 Así, cuanto más breve es el poema, más poder concentra: cuanto más silencio produce, más poético resulta; cuantas menos palabras contiene, más expresivo pretende ser. El poema es también un "aleph del mundo", dice Kamenszain, y podemos pensar que busca decirlo todo afirmando el hecho de que no todo pueda ser dicho y "custodiando", de ese modo, aquello que queda innombrado. Es en ese sentido que el silencio en la poética de Pizarnik constituye a menudo un "símbolo", "gran palabra" o “palabra plena”, retomando el concepto de Franco Rella (1981). A propósito del sentido del silencio en la obra de Ludwing Wittgenstein, Rella plantea que su insistencia en delimitar el terreno de lo decible y de lo pensable, y de limitar la filosofía a ese perímetro ("El sentido del mundo debe quedar fuera del mundo" se dice en el Tractatus logicophilosophicus), constituye un modo de "defender" el espacio de lo que no puede ser nombrado ni atravesado racionalmente. La afirmación del silencio es tan importante como la afirmación de una gran palabra, dice el autor, con la particularidad de que el silencio "se sustrae a la crítica y al análisis, defendiendo también la realidad de la cual se plantea como expresión. El silencio deviene, como en el cuento kafkiano, el "guardián delante de la puerta de la ley."”,12

\footnotetext{
8 "El poeta y su poema" en Prosas completas, p.299

9 "En esta noche, en este mundo" en Los pequeños cantos, Árbol de fuego nro 45, Caracas, 1971.

10 "Escribo contra el miedo...." "Cuando leyó un poema mío (muy doloroso) me dijo que se sintió mejor, que mi poema fue como un bálsamo para ella. Y yo pensé que tal vez la poesía sirva para esto, para que en una noche lluviosa y helada alguien vea escrito en unas líneas su confusión inenarrable y su dolor." Diarios, p.302 (1962)

${ }^{11}$ Kamenszain. La boca del testimonio, p. 80.

12 Rella. El silencio y las palabras, p.22.
} 
En el caso de Pizarnik, como hemos mencionado, el silencio parece vincularse con lo que en ocasiones ella identifica con la poesía, que se encuentra siempre atravesada por la muerte y viceversa ("El poema, como la muerte es transformación"13). Del mismo modo, la sombra -que al igual que el silencio es a la vez una "presencia" en sí misma y la ausencia de otra cosa- custodia también, como el guardián del cuento kafkiano, aquel sentido que se encuentra en el "reverso del mundo", como si cumpliera la exhortación de Paul Celan de oscurecerlo: "dale sentido a tu decir:/ dale sombra"14. No se trata de hablar acerca de la muerte y la poesía sino de hacerlas hablar a ellas por la boca del yo del poema, o de dejarse decir por ellas. Uno de los recursos más explícitos en ese sentido son los "Textos de Sombra", donde Sombra es una suerte de personaje que habla o promueve el habla. En "Presencia de Sombra" leemos:

\footnotetext{
Alguien habla. Alguien me dice.

Extraordinario silencio el de esta noche.

Alguien proyecta su sombra en la pared de mi cuarto. Alguien me mira con mis ojos que no son los míos.

Ella escribe como una lámpara que se apaga, ella escribe como una lámpara que se enciende.

Camina silenciosa.

La noche es una mujer vieja con la cabeza llena de flores.

La noche no es la hija preferida de la reina loca.

Camina silenciosa hacia la profundidad la hija de los reyes.

De demencia la noche, de no tiempo. De memoria la noche, de siempre sombra.
}

La poesía parece identificarse en esta escena de escritura con el "extraordinario silencio" de la noche, que es el habla de alguien, o viceversa; con la proyección de su sombra que coincide y no coincide con la del yo poético. Así, el silencio custodia el habla de la poesía y la realiza como acontecimiento en la escena en la que alguien escribe. Tal como planteaba Lyotard a propósito de los cuadros de Newman, podemos pensar que en Pizarnik lo sublime también tiene que ver con el presente del poema y el acontecimiento de que "aquí y ahora" haya poema en lugar de nada. El poema, alumbrado con la sombra de la muerte, cuestiona "¿hay poesía?" Esta pareciera ser una de las preguntas que deja oír el silencio en la poética de Pizarnik. En uno de los "Fragmentos para dominar el silencio" de Extracción de la piedra de locura de 1968 leemos: "La muerte ha restituido al silencio su prestigio hechizante. Y yo no diré mi poema y yo he de decirlo. Aun si el poema (aquí,

\footnotetext{
13 Pizarnik. Diarios, p.460.

14 "Habla también tú" del libro De umbral en umbral de 1955. En el mismo poema leemos: "dice verdad quien dice sombra." Acaso puedan establecerse algunas similitudes entre Celan y Pizarnik en sus búsquedas poéticas, en su trabajo con lo indecible, en su estética entrecortada. Ana Becciú señaló la existencia de una "hermandad" entre la obra de ambos y recordó que los padres de la poeta eran inmigrantes judíos y que en su casa se hablaba ídish. (Ana Becciú en el marco de la exposición-homenaje a 40 años de la muerte de Pizarnik en el Museo Larreta. 24/5/2012).
} 
ahora) no tiene sentido, no tiene destino.” El poema así vaciado de sentido y destino vale como acontecimiento, apela al silencio para realizarse como acto, parecen decir estos versos.

Por un lado, el silencio es el modo que tiene la muerte de "textualizarse": se resiste a ser dicha, a ser narrada, se "materializa" en silencio y constituye un elemento que "interviene" la escritura fragmentándola, "pulverizándola", como dice Pizarnik. En ese sentido, se trata de un silencio distinto al romántico porque aquí viene a fragmentar el discurso, a cortar la elocuencia, y en ese corte parece radicar lo "nuevo" ("atesoraba palabras muy puras/ para crear nuevos silencios") y lo "moderno" para ella. "Poco me importa ser moderna, pero si mi poesía lo es, se debe, más que nada, a su fragmentación, a su disgregación, a su pulverización.” dice una entrada de su diario de 1968 (p.452.). Al mismo tiempo, esa pulverización señala también la imposibilidad que a menudo Pizarnik comenta en sus Diarios de no poder narrar y de no poder escribir una "prosa normal", como mencionaremos a continuación. Se queja con frecuencia de no poder escribir más que "fragmentos".

\footnotetext{
P. me dijo que mis "Fragmentos para dominar el silencio" son bellísimos y sobre todo nuevo [sic], pero luego dijo algo así como "iino sé adónde vas a llegar!!”. (Hace unos meses I. me preguntó lo mismo). No sé responder a esa pregunta. Nada me gustaría más que saber narrar -o que querer narrar-. Pero esto es imposible. (p.421)

$\mathrm{Y}$ los años pasan y yo quiero escribir una obra extensa en vez de fragmentos. ( $\mathrm{p}$ $415)^{16}$
}

Desde esta perspectiva, podemos pensar que el trabajo con el silencio potencia la palabra poética, y que el "silencio-oro" de la concordancia fugaz cargada de posibilidades y el "silencio-castigo" del fracaso que distingue María Negroni parecen ser, en realidad, el mismo: el silencio aviva la palabra poética porque tiene la posibilidad de matarla. En el poema "Fuga en lila" de El infierno musical, de 1971, leemos esa ambivalencia: "Había que escribir sin para qué, sin para quién./ El cuerpo se acuerda de un amor como encender la lámpara./ Si silencio es tentación y promesa." Ese último verso, que es una frase condicional incompleta, podría completarse con "poesía" y también con "muerte", porque el silencio es "tentación y promesa" de ambas al mismo tiempo. Muerte, poesía y silencio aparecen como recipientes o cajas chinas que se contienen mutuamente y, también,

\footnotetext{
15 Pizarnik. "Verde paraíso" en Los trabajos y las noches de 1965, p.175.

${ }^{16}$ En La boca del testimonio, Kamenszain analiza la voluntad reiterada en los diarios de Pizarnik de escribir una novela, su "obra maestra en prosa".
} 
conforman el lugar de enunciación del yo: "La muerte siempre al lado./ Escucho su decir./ Sólo me oigo.", dice el poema titulado "Silencios" de Los trabajos y las noches, de 1965.

En el texto "El poeta y su poema" escrito en 1962 y publicado como prólogo a una antología en 1968, encontramos otra formulación acerca de la poesía asociada al silencio y al cuestionamiento de lo poético:

\begin{abstract}
Nos vienen previniendo, desde tiempos inmemoriales, que la poesía es un misterio. No obstante la reconocemos: sabemos dónde está. Creo que la pregunta ¿qué es para usted la poesía? merece una u otra de estas dos respuestas: el silencio o un libro que relate una aventura no poco terrible: la de alguien que parte a cuestionar el poema, la poesía, lo poético (...) (p.300)
\end{abstract}

Estas dos respuestas, que podemos asociar a los dos tipos de escritura que la crítica distingue en la obra de Pizarnik, plantean una falsa oposición o dicotomía. Si la escritura "pura" (Mallol, 1996) se vincula a la poesía entendida como "silencio", y por otra parte, la escritura de las "prosas corrosivas" se asocia a la poesía entendida como el relato de quien se lanza a cuestionarla, estas dos escrituras conforman un sistema de reversos (Mallol, Negroni), se completan y se renvían y parecería ser que ambas se constituyen en torno a la "aventura no poco terrible" de cuestionar lo poético o la poesía: ya sea evocando un "silencio perfecto", buscando producirlo en el poema o con él, o ya sea atentando contra él. Por otra parte, entre esos dos tipos de escritura, la lírica y la del "derrumbe lingüístico" (Negroni), acaso podamos distinguir un tercer tipo de escritura, de "prosa normal", como llama Pizarnik a la escritura de sus Diarios (que, tal como señala Mallol se trata de un diario “literaturizado") y al texto de La condesa sangrienta". Andrea Ostrov (2012) señala en el prólogo a la reciente edición de las cartas entre la poeta y el psicoanalista León Ostrov, que la escritura pizarnikiana constituye una sola exploración poética que atraviesa los límites de los géneros y de la escritura pública -o publicada- y los papeles “privados". De este modo, poesía, prosa poética, relatos, artículos, teatro, diarios y cartas podemos pensarlos como parte de una unidad que, retomando el concepto que Gilles Deleuze y Félix Guattari utilizaron para definir la escritura de Kafka, conformarían la "máquina de expresión" o "máquina de escritura" llamada Pizarnik. Una literatura menor o revolucionaria, dicen los filósofos, al revés que la literatura mayor o establecida que va de un contenido dado a buscar la expresión que le conviene, comienza enunciando: la expresión precede al

\footnotetext{
17 “Cuál es mi estilo? Creo que el del artículo de la condesa. (...) Esta prosa de mi diario se parece a lo que llaman una prosa normal. ¿Por qué, cuando escribo, no trato de apelar a ella? Pienso que mi correspondencia con C. C. me hacía bien pues me obligaba a escribirle con claridad. ¿Es una virtud la claridad? Ignoro cuáles son las virtudes. Sólo conozco los deseos. Uno de mis deseos es escribir en una prosa como la de mi artículo sobre la condesa." Diarios, entrada de noviembre de 1968, p.465
} 
contenido, aquella va rompiendo las formas y se ramifica; es así que vivir y escribir no se contraponen. La expresión "arrastra” al escritor, dicen Deleuze y Guattari, obligándolo a emitir sonidos que pertenecen a un futuro desconocido y que en Pizarnik podrían vincularse, entre otras cosas, como hemos mencionado, a la violencia de estado que se volvió sistemática poco después de su muerte ${ }^{18}$. Pizarnik y Kafka se asemejan en la relación de "extranjería" con respecto a la lengua en la que escriben (una de las condiciones de las literaturas menores) y también en la relación "maquinal” que establecen con la escritura. En ese sentido, quizá no es casual que Kafka aparezca como uno de los escritores referidos con mayor entusiasmo por Pizarnik en sus Diarios, es uno de los modelos más fuertes en sus últimos años ${ }^{19}$.

Como en el texto "El silencio de las sirenas" citado en el epígrafe, en el que Ulises atraviesa el mar protegiéndose del canto de las mujeres del mar pero éstas, sabiendo de su defensa, guardan silencio mientras él imagina que están cantando e incluso le parece verlas, Pizarnik transcribe el canto imaginado de una sirena que acaso podamos identificar con la condesa Erzébet Báthory. María Negroni plantea que La condesa sangrienta es el texto clave que constituye una alegoría de la escritura pizarnikiana. Erzébet torturaba y asesinaba muchachas porque creía que de ese modo podía mantener su juventud e "inmovilizar su belleza", dice Pizarnik, lo cual parecería haber constituido, también, una de las obsesiones de la poeta. A través de las distintas configuraciones del silencio, donde se mezclan lo "extraordinario" y "hechizante", lo monstruoso y aterrador, lo inenarrable e irrepresentable, se configura lo sublime en esta poética que pregunta: "aquí y ahora, chay poesía?"

\section{BIBLIOGRAFÍA}

VV.AA, Alejandra. Point of Contact Vol.10, Nro1-2, Syracouse University Press, New York, 2010.

Aguilar, Gonzalo (2009); Episodios cosmopolitas en la cultura argentina, Buenos Aires, Santiago Arcos.

Badiou, Alain (1990); Manifiesto por la filosofía, Buenos Aires, Nueva Visión.

Burke, Edmund (1757). Indagación filosófica sobre el origen de nuestras ideas acerca de lo bello y lo sublime, Alianza Editorial, 2005.

Celan, Paul; Obras completas, Madrid, Editorial Trotta, 2004.

\footnotetext{
${ }_{18}$ Esta es la hipótesis que el lingüista Tony Thorne plantea en Countess Dracula (2001) acerca de La condesa sangrienta y que Tomás Eloy Martínez refiere en un artículo publicado en La nación el 12/5/2001.

19 "Leer sin falta un párrafo de K. como quien lee la Biblia."p.447 "Salvo Kafka, la literatura no me gratifica." Diarios, p.463
} 
Deleuze, Gilles; GUATTARI, Félix (1975); Kafka. Por una literatura menor, México, Era, 1978.

Heidegger, Martín (1936); Arte y poesía, México, Fondo de Cultura Económica, 1958.

Kamenszain, Tamara (2007); La boca del testimonio, Buenos Aires, Norma.

(2000); Historias de amor y otros ensayos sobre poesía, Bs As, Paidós.

Kant, Immanuel (1790); Crítica del Juicio, Madrid, Espasa-Calpe, 1999.

Editorial, 1990.

(1764); Observaciones acerca del sentimiento de lo bello y de lo sublime, Alianza

Lyotard, Jean-François; (1988); Lo inhumano, Buenos Aires, Manantial, 1998.

Mallol, Anahí (2003); Elpoema y su doble, Buenos Aires, Simurg.

Orbis Tertius (2-3).

(1996); "Distanciamiento y extrañeza en la obra de Alejandra Pizarnik",

Negroni, María (2003); El testigo lúcido. La obra de sombra de Alejandra Pizarnik, Rosario, Beatriz Viterbo.

Pizarnik, Alejandra, Poesía completa, Barcelona, Editorial Lumen, 2000.

; Prosa completa, Barcelona, Editorial Lumen, 2002.

; Cartas. Alejandra Piqarnik/León Ostrov, Buenos Aires, Eduvim, 2012.

; Diarios, Barcelona, Editorial Lumen, 2003.

Rella, Franco (1981); El silencio y las palabras. El pensamiento en tiempo de crisis, Barcelona, Paidós, 1992.

Sartre, Jean-Paul (1947); Situaciones I. Buenos Aires, Losada, 1960.

Sontag, Susan (1967); Estilos radicales, Madrid, Suma de Letras, 2005.

Starobinski, Jean (1989); La mélancolie au miroir. Conférences, essais et leçons du Collège de France, Paris, Julliard.

Steiner, George (1967); Lenguaje y silencio, Gedisa, 2003. 